\title{
Main pulmonary artery to innominate artery shunt during hybrid palliation of hypoplastic left heart syndrome
}

\author{
Christopher A. Caldarone, MD, Lee N. Benson, MD, Helen Holtby, MD, and
}

Glen S. Van Arsdell, MD, Toronto, Ontario, Canada

B ilateral pulmonary artery banding with ductal stenting (PAB-DS) hybrid procedures represent an evolving management strategy for neonates requiring single ventricle palliation. ${ }^{1}$ A concern with this strategy is the possibility of immediate or delayed obstruction in the aortic isthmus after stent deployment, which in patients with aortic atresia can lead to acute coronary and cerebral hypoperfusion. ${ }^{2}$ Obstruction can occur immediately as a result of stent maldeployment, within a few hours from ductal remodeling after discontinuation of prostaglandins, or late as a result of fibrosis in the distal stent. ${ }^{1,3,4}$ A potential solution to this problem is the placement of a main pulmonary artery-to-innominate artery (MPA-IA) shunt, which is analogous to a reversed modified Blalock-Taussig shunt (Figure 1).

\section{Technique}

After median sternotomy and heparinization, bilateral pulmonary artery bands are placed. The MPA-IA is anastomosed with a side-biting clamp on the main pulmonary artery anterior to the origin of the right pulmonary artery with a $3.5-\mathrm{mm}$ polytetrafluoroethylene graft. Because the main pulmonary artery is typically dilated, the placement of the clamp is well tolerated. The distal anastomosis is then constructed to the proximal innominate artery with standard anastomotic technique. Flow in the shunt is directed away from the main pulmonary artery to the innominate artery; it is therefore unnecessary to place the anastomosis distally near the subclavian origin. On the contrary, the shunt should be as proximal as possible to maximize flow through it. Ductal stent deployment and atrial septostomy or stenting are then performed.

\section{Results}

The MPA-IA shunt has been used in 2 neonates at the Hospital for Sick Children after obtaining approval from the research ethics board and informed parental consent.

A 3.2-kg female neonate with hypoplastic left heart syndrome (aortic atresia) underwent PAB-DS at 8 days old. The MPA-IA shunt was placed without incident. After ductal stent deployment,

\footnotetext{
From the Division of Cardiovascular Surgery, The Hospital for Sick Children, Toronto, Ontario, Canada.

Received for publication May 10, 2005; revisions received May 30, 2005; accepted for publication June 7, 2005.

Address for reprints: Christopher Caldarone, MD, Division of Cardiovascular Surgery, The Hospital for Sick Children, 555 University Ave, Toronto, Ontario M5G 1X8, Canada (E-mail: christopher.caldarone@ sickkids.ca).

J Thorac Cardiovasc Surg 2005;130:e1-e2

$0022-5223 / \$ 30.00$

Copyright $\odot 2005$ by The American Association for Thoracic Surgery

doi:10.1016/j.jtcvs.2005.06.010
}

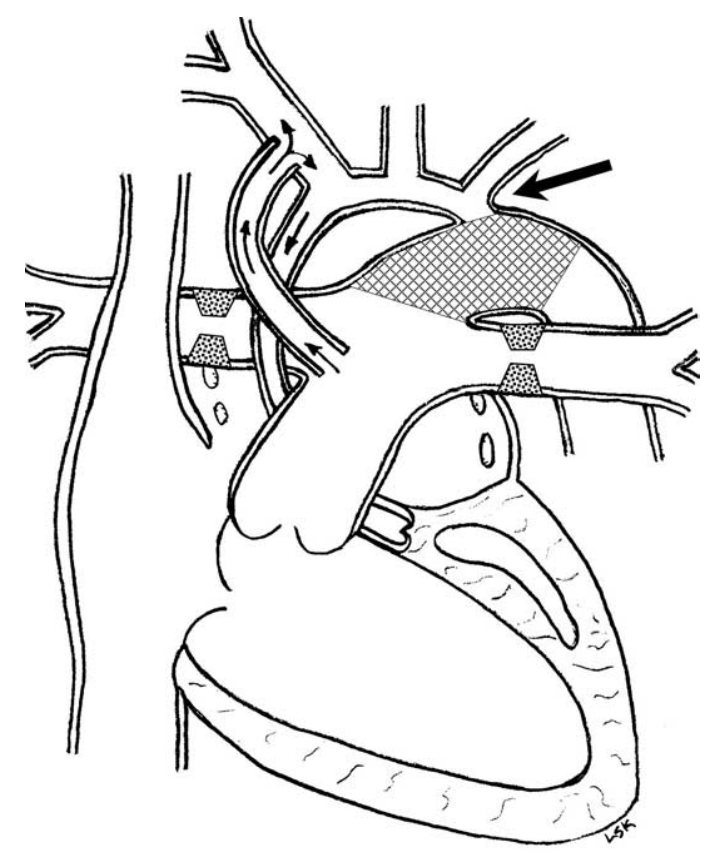

Figure 1. Hypoplastic left heart syndrome with aortic atresia is depicted after bilateral pulmonary artery banding (stippled areas) and ductal stenting (crosshatched area). MPA-IA shunt provides source of blood flow to aortic arch (small arrows) in patients in whom retrograde flow across aortic isthmus is obstructed (large arrow).

the chest was closed and catheter-based atrial septostomy was performed. During septostomy, the patient required adenosine and cardioversion for atrial arrhythmias. She thereafter remained in hemodynamically stable condition, but a severe coagulopathy developed. A subsequent mediastinal exploration did not demonstrate any significant bleeding, and the sternum was reclosed. Frequent echocardiograms were performed, and antegrade shunt flow was noted. After a focal seizure on postoperative day 11, a head computed tomographic scan was obtained, and no evidence of cerebral emboli was noted. She was discharged home on postoperative day 23 and is free of symptoms and awaiting secondstage palliation. Weekly outpatient echocardiograms have demonstrated prograde shunt flow.

A 2.4-kg neonate with mosaic Turner syndrome and hypoplastic left heart syndrome (aortic atresia) underwent uneventful PABDS, including placement of the MPA-IA shunt and atrial stent. She had hemodynamic stability in the postoperative period, but remained ventilated, gained weight slowly, and had a measured 
pulmonary-to-systemic blood flow ratio of approximately 2 to 1 . After an extubation attempt on postoperative day 37, necrosing enterocolitis developed, later followed by severe adenoviral pneumonitis. Progressive pulmonary failure led to the requirement for extracorporeal membrane oxygenation. Weekly echocardiographic evaluations demonstrated shunt patency. Because of progressive pulmonary deterioration, care was withdrawn on postoperative day 53. Subsequent postmortem examination demonstrated shunt patency and no evidence of cerebral embolization.

\section{Comment}

Our concern that retrograde aortic arch flow could become obstructed after PAB-DS prompted us empirically to use a protective shunt in patients with absent prograde aortic flow. The shunt can be considered a "reversed" modified Blalock-Taussig shunt in that flow in the shunt passes from the systemic outflow (main pulmonary artery) to the innominate artery and aortic arch. Technically, the addition of a shunt to PAB-DS is straightforward. The ability of the shunt to protect against a loss of retrograde aortic flow and subsequent myocardial and cerebral ischemia remains unproven. In addition, thrombi originating from the shunt could result in cerebral or myocardial emboli, although these effects have not been detected in our patients.

Because PAB-DS is a relatively new procedure, a comprehensive evaluation of the incidence of compromised retrograde aortic flow in patients with aortic stenosis or atresia is not available.
Nevertheless, it has been reported by others ${ }^{1,2}$ and also noted by our group on post-PAB-DS follow-up catheterizations.

During PAB-DS, acute obstruction of retrograde flow and subsequent coronary hypoperfusion would necessitate extracorporeal membrane oxygenation support during attempts to restore perfusion. Standard resuscitation with extracorporeal membrane oxygenation, however, would require additional emergency cannulation of the hypoplastic ascending aorta or innominate artery to restore coronary perfusion. We therefore have adopted the policy of routinely placing the shunt before deployment of the ductal stent and propose the use of the MPA-IA shunt as a surgical strategy to reduce the risk of the PAB-DS procedures in patients with absent or limited prograde aortic flow.

\section{References}

1. Akintuerk H, Michel-Behnke I, Valeske K, Mueller M, Thul J, Bauer J, et al. Stenting of the arterial duct and banding of the pulmonary arteries: basis for combined Norwood stage I and II repair in hypoplastic left heart. Circulation. 2002;105:1099-103.

2. Pizarro C, Murdison KA. Off pump palliation for hypoplastic left heart syndrome: surgical approach. Semin Thorac Cardiovasc Surg Pediatr Card Surg Annu. 2005;8:66-71.

3. Bacha EA, Hijazi ZM. Hybrid procedures in pediatric cardiac surgery. Semin Thorac Cardiovasc Surg Pediatr Card Surg Annu. 2005; 8:7885.

4. Gewillig M, Boshoff DE, Dens J, Mertens L, Benson LN. Stenting the neonatal arterial duct in duct-dependent pulmonary circulation: new techniques, better results. J Am Coll Cardiol. 2004;43:107-12. 